\title{
3-methyl-1-[3-(3-methyl-2-oxobutylidene)-1,4-dihydro-6-nitro-quinoxalin- 2-ylidene]butan-2-one.
}

\section{Ibrahim Bouabdallah*, Ismail Zidane, Rachid Touzani, Fouad Malek, Mohamed El Kodadi and Abdelkrim Ramdani.}

Laboratoire de Chimie Organique Physique, Département de Chimie, Faculté des Sciences, Université Mohamed Premier, BP 524, 60000, Oujda , Maroc.

E-mail : Bouabdallah@sciences.univ-oujda.ac.ma. ra@sciences.univ-oujda.ac.ma.

Received: 13 November 2003 / Accepted: 24 February 2004 / Published: 29 March 2004

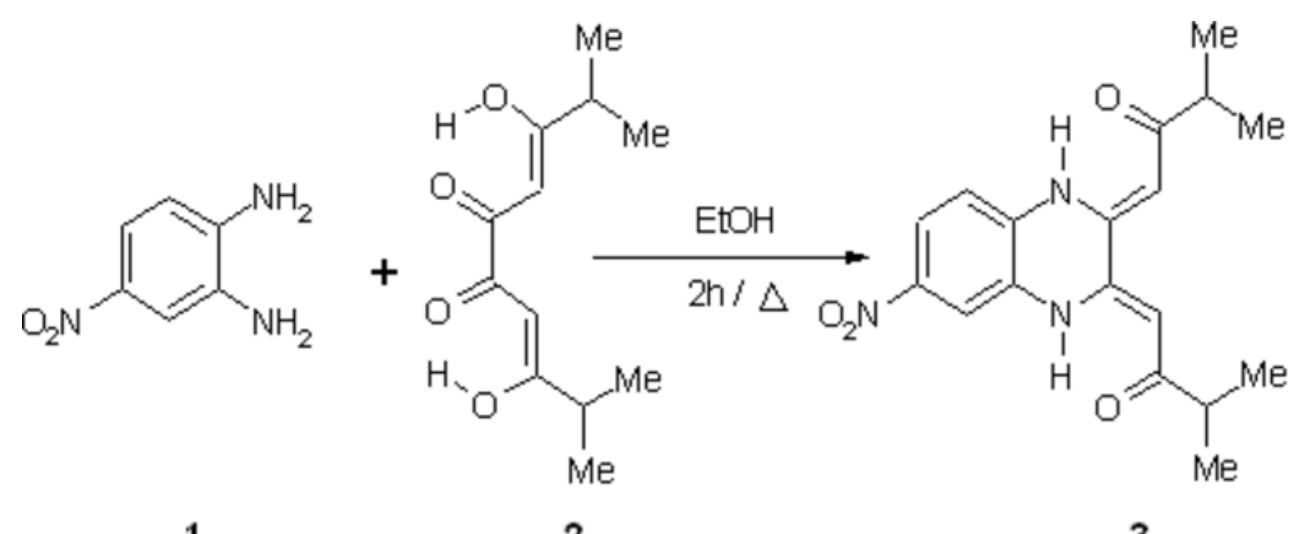

1

2

3

To a solution of 3,8-dihydroxy-2,9-dimethyl deca-3,7-diene-5,6-dione 2 [1] (1.278 g, 5.6 mmol) in absolute ethanol (20 mL) was added the 4-nitro-orthophenylenediamine $1(0.865 \mathrm{~g}, 5.6 \mathrm{mmol})$ and the mixture was refluxed for 2 hours [2]. The yellow precipitate 3 was filtered off, washed with ethanol and dried in air.

Yield: (780 mg , $41 \%)$.

Melting point: $150-152^{\circ} \mathrm{C}(\mathrm{EtOH})$.

IR $\left(\mathrm{KBr}, \mathrm{cm}^{-1}\right): 2920\left(\mathrm{CH}\right.$ of $\left.\mathrm{CH}_{3}\right) ; 1610(\mathrm{C}=\mathrm{O})$.

${ }^{1}$ H-NMR (200 MHz, CDCl3, d, ppm): 14.26 (s, 2H, N-H); 14.21 (s, 2H, N-H); 7.95 (d, 1H, C-H Benz, J = 8.4 Hz); 7.91 (s, 1H, C-H Benz); 7.05 (d, 1H, C-H Benz, J = 8.4 Hz); 5.86 (s, 1H, =CH); 5.82 (s, 1H, =CH); 2.72 (m, 2H, $\left.\mathrm{CH}\left(\mathrm{CH}_{3}\right)_{2}, \mathrm{~J}=6.9 \mathrm{~Hz}\right) ; 1.21\left(\mathrm{~d}, 12 \mathrm{H}, \mathrm{CH}_{3}, \mathrm{~J}=6.9 \mathrm{~Hz}\right)$.

HR/MS $\left(\mathrm{C}_{18} \mathrm{H}_{21} \mathrm{~N}_{3} \mathrm{O}_{4}\right)$ : calc 343.1541; found 343.1532.

\section{References and notes:}

1. Bouabdallah, I.; Zidane, I.; Malek, F.; Touzani, R.; El Kodadi, M. and Ramdani, A. 


\section{Molbank, 2003, M 345.}

2. Waring, M.; Ben-hadda, T.; Kotchevar, A.; Ramdani, A.; Touzani, R.; El Kadiri, S.; Hakkou, A.; Bouakka, M. and Ellis, T. Molecules, 2002, 7, 641-656.

Sample Availability: Available from the Authors.

(C) 2004 MDPI. All rights reserved. 